\title{
Comparison of commercial nanoliquid chromatography columns for fast, targeted mass spectrometry-based proteomics
}

\begin{abstract}
Aim: We compared four commonly used, commercially available reverse phase nanoLC columns for identification/determination of Wnt/ $\beta$-catenin-related pathway proteins. Materials \& methods: The columns were: Chromolith $^{\oplus}$ (silica monolith; Merke Millipore, MA, USA), PepMap ${ }^{\text {тM }}$ (porous particles; Thermo Fisher Scientific, MA, USA), Accucore $^{\mathrm{TM}}$ (solid core particles; Thermo Fisher Scientific) and PepSwift ${ }^{\mathrm{TM}}$ (organic monolith; Thermo Fisher Scientific). Results: The peak capacity of the columns varied from 100 (Pepswift) to 190 (Accucore) (for 30 min gradients). All columns enabled identification/detection of GSK3 $\beta$ and $\beta$-catenin in the complex samples. However, even the columns with higher peak capacities could not enable detection of the somewhat less abundant proteins AXIN2 and TNKS2. The monoliths were more prone to retention time instability when sample complexity increased. Conclusion: We find that commercial nanoLC columns, although featuring different morphologies and peak capacities, provided surprisingly few practical differences for relatively fast, targeted determination of proteins.
\end{abstract}

Lay abstract: The measurement of proteins (which can indicate diseases) in biological samples is commonly done with nonspecific approaches (can give rise to false results) that can be tedious and time consuming, especially when many proteins are to be measured from the same sample. Nanoliquid chromatography-mass spectrometry is an alternative approach that is very specific, and can be used to measure many proteins at once. There are several variants of nanoLC (i.e., nanoLC columns that are connected to the MS), but we have found that it is rather indifferent which nanoLC column is used for fast analysis. Hence, new nanoLC variants are called for to push the technique further.

First draft submitted: 12 February 2016; Accepted for publication: 26 February 2016; Published online: 16 March 2016

Keywords: Chromatography $\bullet$ mass spectrometry $\bullet$ parallel reaction monitoring $\bullet$ SILAC - targeted proteomics

Targeted proteomics with nanoLC-ESIMS/MS can be used to selectively detect/ quantify specific proteins, often within short analysis times compared with more comprehensive approaches (e.g., $30 \mathrm{~min}$ instead of several hours) [1-3]). Operating the MS in selected/parallell reaction monitoring (SRM/PRM) [4] increases sensitivity in targeted proteomics. However, high performance separation columns are also required to resolve compounds prior to MS detection, reducing ion suppression during the electrospray process. A key descriptor of LC resolution is the peak capacity of the column (i.e., the number of compounds that can be chromatographically separated) $[5,6]$. Several variants of nanoLC columns can provide high peak capacity, for example,
Tore Vehus ${ }^{*, 1}$, Kristina Erikstad Seterdal' ${ }^{1}$, Stefan Krauss ${ }^{2}$, Elsa Lundanes ${ }^{1}$ \& Steven R Wilson ${ }^{1}$

'Department of Chemistry, University of Oslo, P.O. 1033 Blindern, NO-0315 Oslo, Norway

¿Unit for Cell Signaling, SFI-CAST Biomedical Innovation Center, Oslo University Hospital, Rikshospitalet, NO-0027 Oslo, Norway *Author for correspondence: Tel.: +4797518113 toreveh@mn.uio.no 
columns packed with solid core particles or totally porous particles, and silica-based monoliths and organic monoliths [7-9]. All of these column variants can provide high-resolution separations for comprehensive proteomics [9-12]. Similar columns have previously been partly compared regarding peak capacity, evaluated with simple standards [13], but a comparison for 'real-life' proteomics (e.g., relatively fast gradients, very complex samples), with a focus on column robustness (performance with standards vs complex samples), has not been performed.

We wished to investigate commercially available columns with the above-mentioned morphologies regarding performance for determination of central proteins of the cancer-associated $\mathrm{Wnt} / \beta$-catenin pathway [14] (a key focus of our research $[15,16]$ ). These proteins are present at moderate-low concentrations $(60-<1 \mathrm{ng} / \mu \mathrm{l})$. Specifically, peak capacity, peak shape, carryover and retention time repeatability were assessed.

\section{Materials \& methods}

\section{Sample preparation}

Recombinant APC (H00000324-Q01) and AXIN2 (H00008313-Q01) were purchased from Abnova (Tapei City, Taiwan). Glycogen synthase $3 \beta$ (GSK3 $\beta$ ) were from Life Technologies (CA, USA) and $\beta$-catenin (12-537) from Millipore (MA, USA). The polyADP-ribosylation polymerization (PARP)-domain of human tankyrase2 (TNKS2) was produced as described in [17]. All amino acid sequences can be found in Supplementary Table 1.

Each standard protein was digested with trypsin (Promega, Madison, WI, USA). Briefly, $10 \mu \mathrm{g}$ of each protein was dissolved in $1 \mathrm{ml} 8 \mathrm{M}$ urea (Sigma Aldrich) dissolved in $50 \mathrm{mM}$ Tris- $\mathrm{HCl} \mathrm{pH} 8.0$ (Sigma Aldrich). The samples were reduced in $5 \mathrm{mM}$ dithiothretiol (Sigma Aldrich) at $37^{\circ} \mathrm{C}$ for $30 \mathrm{~min}$ and alkylated with $15 \mathrm{mM}$ iodoacetamide for $15 \mathrm{~min}$ in the dark. The urea concentration was reduced to $1.5 \mathrm{M}$ by adding $50 \mathrm{mM}$ Tris- $\mathrm{HCl} \mathrm{pH}$ 8.0. Trypsin was added to a protein:enzyme ratio of $1: 20$, and incubated over night at $37^{\circ} \mathrm{C}$. The digested standards were desalted using solid phase extraction (SPE) on reversed phase (RP) $\mathrm{C}_{18}$ cartridges (Bond Elut $\mathrm{C}_{18}, 100 \mathrm{mg}$, Agilent, CA, USA) with water (Millipore) and eluted in $1 \mathrm{ml} 80 \%$ acetonitrile (ACN, HiPerSolv CHROMA$\mathrm{NORM}^{\circledast}$, VWR, Radnor, PA, USA) with $0.1 \%$ formic acid (FA, Sigma Aldrich) (v/v) and dried with a SpeedVac (Thermo Fischer Scientific; former Savant, MA, USA). Each standard were reconstituted in $0.1 \%$ (v/v) TFA (Sigma Aldrich) to a final concentration of $10 \mu \mathrm{g} / \mathrm{ml}$.

A set of external standard mixtures (ExSMix) containing $1,0.5,0.1,0.05,0.01,0.005,0.001,0.0005$ and
$0.0001 \mu \mathrm{g} / \mathrm{ml}$ of each protein standard were prepared by appropriate dilution with $0.1 \%(\mathrm{v} / \mathrm{v})$ TFA.

HCT15 cells (American Type Culture Collection, ATCC, VA, USA) were cultured in RPMI 1640 medium (Life Technologies) supplemented with 10\% fetal bovine serum (Life Technologies) and penicillin streptomycin (Life Technologies) and harvested with trypsin EDTA (Life Technologies) at 80\% confluence. The cells were counted and washed in phosphate-buffered saline (Oslo University Hospital, Oslo, Norway). The proteins were extracted and digested using the filter-aided sample preparation protocol [18]. Briefly, 1 million cells were resuspended in $200 \mu \mathrm{l}$ lysis buffer, heated for $15 \mathrm{~min}$ at $70^{\circ} \mathrm{C}$ and sonicated for $5 \mathrm{~min}$. Debris was removed with centrifugation at $13,000 \mathrm{rpm}$ for $10 \mathrm{~min}$ in a thermostated centrifuge at $20^{\circ} \mathrm{C}$ (Eppendorf, Hamburg, Germany). The protein concentration was determined using Bradford Assay (Bradford Quick Start Assay, Bio-Rad, CA, USA) at absorbance of $595 \mathrm{~nm}$ with bovine serum albumin (Sigma Aldrich) used as calibration standards. About $100 \mu \mathrm{g}$ protein was added to $10 \mathrm{kDa} 0.5 \mathrm{ml}$ filter devices (Millipore). The filter-aided sample preparation two-step digestion protocol with Trypsin-LysC mix (Promega) (1:20 protein:enzyme ratio) was followed [18]. The peptides were desalted using the above-described SPEprocedure. Peptide concentrations were determined using a NanoDrop2000 instrument (Thermo Fisher Scientific) with absorbance at $205 \mathrm{~nm}$ with $31 \mathrm{mg} / \mathrm{ml}$ absorption coefficient. The samples were diluted to a final concentration of $1 \mathrm{mg} / \mathrm{ml}$ with $0.1 \%(\mathrm{v} / \mathrm{v})$ TFA.

An internal standard protein solution (IS ${ }_{\text {proo }}$ ) was prepared by SILAC labeling of HEK293 (ATCC) and HCT15 cells according to the procedure described by Ong \& Mann [19] with ${ }^{13} \mathrm{C}_{6}{ }^{15} \mathrm{~N}_{4}$-arginine and ${ }^{13} \mathrm{C}_{6}$-lysine (+10.008 and $+6.020 \mathrm{Da}$, respectively) (Thermo Fisher Scientific) supplemented to RPMI1640 Media for SILAC acquired from Thermo Fisher Scientific. The labeled cell lines were subsequently lysed as described above and added to samples prior to protein digestion. Heavy amino acid incorporation was verified with data-dependent LC-MS/MS analysis of nonlabeled cell lines and labeled cell lines (data not shown).

\section{Treatment of cell lines with G007-LK}

The colon carcinoma cells were seeded $(100,000$ cells/ well) in 6-well plates (Nunc ${ }^{\mathrm{TM}}$ Cell-Culture Treated Multidishes, Thermo Fisher Scientific). RPMI1640 were used for HCT15 and COLO320DM (ATCC) cells with incubation in $5 \% \mathrm{CO}_{2}$, and Leibowitz L-15 medium (Thermo Fisher Scientific) for SW480 (ATCC) cells with incubation in $0 \% \mathrm{CO}_{2}$. After $24 \mathrm{~h}$, the medium was removed and the tankyrase inhibitor G007-LK [17] (dissolved in dimethylsulfoxide (Sigma 
Aldrich) was added to a final concentration of $1 \mu \mathrm{M}$ in the cells' respective medium. An equal volume of dimethylsulfoxide was added as negative control. After $24 \mathrm{~h}$ of incubation the cells were harvested and processed as described above.

Three biological replicates were made and analyzed, with exception of COLO320DM and SW480 cells, were treated cells were analyzed in duplicates.

\section{LC instrumentation}

A NanoLC1000 pump from Thermo Fisher Scientific was used in this study. The mobile phase A (MP A) contained $0.1 \%(\mathrm{v} / \mathrm{v})$ FA in $\mathrm{H}_{2} \mathrm{O}\left(\mathrm{Optima}^{\circledR} \mathrm{LC} / \mathrm{MS}\right.$, Fisher Scientific, part of Thermo Fisher Scientific) and mobile phase B (MP B) contained $0.1 \%(\mathrm{v} / \mathrm{v})$ FA in $\mathrm{ACN}$. The pre- and analytical columns were coupled through a stainless steel T-piece (Valco, VICI AG International, Schenkon, Switzerland). Each gradient of $30 \mathrm{~min}$ was followed with a linear increase to $95 \%$ MP B for 10 min and a $10-15$ min hold at $95 \%$ MP B. Each pre- and analytical column was equilibrated with at least six column volumes.

The Acclaim $^{\circledR}$ PepMap RSLC (PepMap ${ }^{\text {TM}}$ ) $75 \mu \mathrm{m} \times 20 \mathrm{~mm}$ and $50 \mu \mathrm{m} \times 150 \mathrm{~mm}$ particle packed preand analytical columns, the PepSwift ${ }^{\circledR} 200 \mu \mathrm{m} \times 5 \mathrm{~mm}$ and $100 \mu \mathrm{m} \times 250 \mathrm{~mm}$ monolithic poly-styrene divinylbenzene (PS-DVB) pre- and analytical columns, the Accucore $^{\mathrm{TM}} 75 \mu \mathrm{m} \times 150 \mathrm{~mm}$ solid core particle packed column were from Thermo Fisher Scientific and the $100 \mu \mathrm{m} \times 50 \mathrm{~mm}$ and $50 \mu \mathrm{m} \times 150 \mathrm{~mm}$ Chromolith $^{\circledR}$ Caprod $^{\circledR}$ silica monolithic pre- and analytical columns were from Merck-Millipore.

\section{MS \& MS/MS parameters}

The electrospray voltage was set to $1.8 \mathrm{kV}$ for the $2 \mu \mathrm{m}$ inner diameter (ID) stainless steel emitter (Thermo Fisher Scientific), the 5 and $8 \mu \mathrm{m}$ ID New Objective Emitters (New Objective, Woburn, MO, USA). The Accucore and PepSwift were connected to the MS through PicoTip ESI emitters fitted for the column flow rate used. The PepMap and Chromolith columns were connected to stainless steel emitters.

A Q Exactive ${ }^{\mathrm{TM}}$ Hybrid Quadrupole-Orbitrap mass spectrometer (Thermo Fisher Scientific) was used for the entire study. Two main methods were used, full-MS with subsequent data-dependent MS/MS (ddMSMS) and targeted-MS/MS with selected ions from the proteotypic peptides chosen. In full-MS, the resolution was set to 140,000 at $\mathrm{m} / \mathrm{z} 200$, automatic gain control (AGC) to $1,000,000$, maximum inject time to $100 \mathrm{~ms}$ and scan range $\mathrm{m} / \mathrm{z} 350-1850$. The 10 most intense ions were selected and fragmented using normalized collision energy (NCE) of $25 \%$ and the MS/MS scans were acquired with; resolution of 70,000, AGC target value of 100,000, and maximum inject time of $500 \mathrm{~ms}$. Dynamic exclusion was enabled for $20 \mathrm{~s}$, and charge states of 1 and $>7$ were rejected for fragmentation.

For targeted MS/MS, each target was monitored in a retention time window of \pm 4 min relative to the retention time determined by ddMSMS, and either operated in single or duplexing mode. For single ion fragmentation, the maximum injection time was set to $500 \mathrm{~ms}$, with an AGC target value of 100,000, and a resolution of 140,000 . The isolation width was set to $\mathrm{m} / \mathrm{z} 4.0$ and the NCE to $25 \mathrm{eV}$.

In duplex mode, the resolution was decreased to 35,000 , the maximum inject time lowered to $100 \mathrm{~ms}$ and the AGC target value kept unaltered. Each target was fragmented with an isolation of $\mathrm{m} / \mathrm{z} 2.0$ and NCE of $25 \mathrm{eV}$.

\section{Peptide identification \& proteotypic peptide selection}

Using the Skyline software (v2.5) [20], a theoretical tryptic digest of each protein standard was made and together with data-dependent LC-MS/MS runs for each column, a set of proteotypic peptides was selected for each protein (Supplementary Table 2). The peptides selected were checked for uniqueness against the Uniprot database [21] and only peptides selectively representing the proteins of interest were chosen as proteotypic peptides. Peptides containing cysteine, methionine, serine, tyrosine and threonine were avoided if other possibilities were available. A minimum of $3 \mathrm{~m} / \mathrm{z}$ transitions above $350 \mathrm{~m} / \mathrm{z}$ were chosen (Precursor and fragment $\mathrm{m} / \mathrm{z}$ are shown in Supplementary Table 2).

\section{Data processing}

All chromatograms were analyzed with Xcalibur software (v2.1, Thermo Fisher Scientific) and Proteome Discoverer (v1.4, Thermo Fisher Scientific) with the Sequest algorithm were used for searching against the protein sequences found in Supplementary Table 1 and Supplementary Excel File, and against the Uniprot database for comprehensive identification. Peak capacity was measured for at least 5 peptides manually with a confidence of $\pm 0.01 \mathrm{~min}$. Peak widths, heights and areas were measured manually, and peak capacity $\left(n_{c}\right)$ at half peak height was calculated according to Equation 1,

$$
\mathbf{n}_{\mathrm{c}}=\frac{\mathbf{t}_{\mathrm{R}, \text { last }}-\mathbf{t}_{\mathrm{R}, \text { first }}}{\overline{\mathbf{W}_{0.5}}}
$$

where

$\overline{\mathrm{W}_{0.5}}$ is average peak width at half peak height, $\mathrm{t}_{\mathrm{R}, \text { first }}$ and $t_{R \text {, last }}$ are the retention times for the first and last eluting peak, respectively. 
Data-dependent MS/MS

For identification in ddMSMS of complex samples, maximum two missed cleavages, maximum $10 \mathrm{ppm}$ precursor and 0.6 Da mass tolerance, respectively, were allowed, combined with a false discovery rate of 0.01 . A minimum of two peptides, where at least one had to be unique were used for positive identification. Carbamidomethylation was set as a static modification and oxidation of methionine as dynamic. When labeled samples were processed, heavy lysine and arginine were set as fixed modifications.

\section{Targeted MS/MS}

Targeted MS/MS data acquired at resolutions of 140,000 and 35,000 were extracted using 7 and $25 \mathrm{ppm}$, respectively. Identification of proteins in targeted MS/MS was done manually with Xcalibur software.

\section{Statistical analysis}

Optimization of flow rate in terms of measured peak capacity was based on one injection per flow rate, and measured for $>5$ peptides eluting throughout the gradient (Supplementary Figures 1-6). For the optimal separation conditions, the values are based on at least three injections, and more than five peptides. Peak capacity relative variation was less than $10 \%$. Identifications in complex samples were based on at least three replicates.

For statistical analysis, F-test and two-sided student t-test were used, where $n \geq 3$.

\section{Results \& discussion Framework}

The RP columns investigated were Chromolith CapRod $\left(\mathrm{C}_{18}\right.$ silica monolith), PepMap $\left(\mathrm{C}_{18}\right.$ porous particles), Accucore ( $\mathrm{C}_{18}$ solid core particles) and PepSwift (PS-DVB organic monolith). These represent the most common used columns/morphologies in modern bottom-up proteomics. The columns available had some variations in dimensions $(50-100 \mu \mathrm{m}$ IDs and 15-25 cm length); identical dimensions were not commercially available for all columns, but at optimum conditions the $t_{G} / t_{0}$ were almost identical (see below) and comparison of performance could be done, using the procedure described by Wang et al. [6]. The linear separation gradient was set to $30 \mathrm{~min}\left(=\mathrm{t}_{\mathrm{G}}\right)$, with a total analysis time of $1 \mathrm{~h}$ (including washing steps, equilibration and sample loading); this was considered to be an acceptable compromise between speed and risk of ion suppression. For each column, the gradient was adjusted so that the last eluting peptide of interest eluted at $t_{G}$, One column per instrument maker was investigated; batch to batch variations of these columns is minimal $(2-5 \%$ variation $[22,23])$. A standard mobile phase consisting of water, $0.1 \% \mathrm{FA}$, and $\mathrm{ACN}$ were used for all columns. Proteins studied were AXIN2, $\beta$-catenin,GSK3 $\beta$ and TNKS2, which are key targets in our efforts in developing novel cancer therapeutics [15]. Additionally, the C-terminal of APC was included, and served as a negative control for protein identification in the APC-mutated colon carcinoma cell lines. The amounts of complex samples loaded onto each system were between 0.5 and $1 \mu \mathrm{g}$, amounts that are common in proteomics experiments $[24,25]$ and well below the precolumn capacities reported by the manufacturers. The LC-MS/MS system set-up was considered 'healthy' as 40 proteins/separation minute could be identified in comprehensive mode (Supplementary Excel File).

\section{Comparison of column performance, using a standard mixture}

To compare the nanoLC columns' performance for 30 min gradients, the flow rate and gradient composition were optimized for each column with regards to peak capacity according to the procedure described by Wang et al. [6]. The definition used for peak capacity is found in Eq.1 (Materials and methods) A key point is to fully exploit the separation window, ensuring that the most hydrophobic analytes elute at the end of the gradient $\left(\mathrm{t}_{\text {final peak }}=\mathrm{t}_{\mathrm{G}}\right)$. The sample was the ExSMix (tryptic peptides from recombinant APC, AXIN2, $\beta$-catenin, GSK3 $\beta$ and tankyrase2, see Materials and methods). Table 1 shows the peak capacity and peak asymmetry for each column set-up, as well as the enabling solvent conditions. The highest peak capacity was obtained with the solid core particle packed column set-up, with an average peak capacity close to 190 (Supplementary Figure 7); approximately 1.5-times larger compared with the second-best performing column (the silica monolith, peak capacity $=130$ ) with our conditions. The solid core particle packed based column also provided the least peak tailing and the narrowest peaks of the columns included in this study, with an average asymmetry of 1.1 and a base peak width of $10 \mathrm{~s}$. The two monolithic columns tested displayed more peak tailing compared with the particle-based columns (1.4-1.5 vs 1.1-1.3). The optimal linear gradient composition was the same $\left(36 \%\right.$ solvent $\mathrm{B}$ at $\left.\mathrm{t}_{\mathrm{G}} \approx 30 \mathrm{~min}\right)$ for the columns with $\mathrm{C}_{18}$ stationary phases. For the less hydrophobic PS-DVB column, the end gradient composition needed to be significantly lower (20\% solvent $\mathrm{B}$ at $\mathrm{t}_{\mathrm{G}}$ ) to ensure $\mathrm{t}_{\text {final }} \approx \mathrm{t}_{\mathrm{G}}$. With the flow rates investigated, no major effects on signal intensity were observed (two-fold changes or less, Supplementary Figures 5 \& 6). The average relative standard deviations (RSDs) for the $t_{R}$ in the ExSMix were 0.3, 0.2, 0.4 and $1.0 \%$ for the Chromolith, Accucore, PepMap and PepSwift, respectively. Carryover was negligible (<LOD) for all 


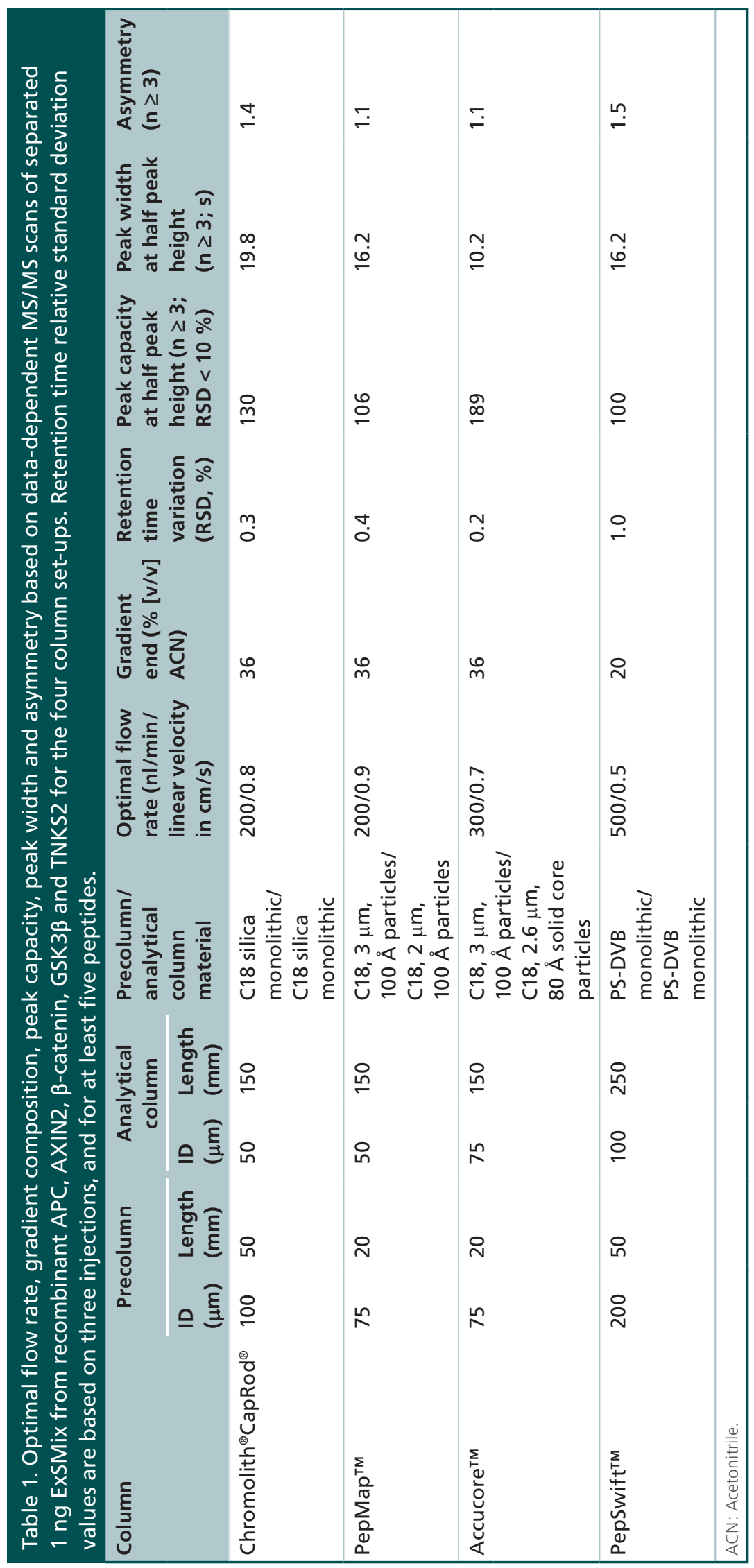


columns regarding the analytes and concentrations investigated in this study.

\section{Comparison of column performance, using complex samples}

Using the optimized LC conditions for each column, and ddMS/MS acquisition, 17 proteotypic peptides (Figure 1) of proteins associated with the $\beta$-catenin degradasome were selected for further targeted MS/MS studies.

The effect of sample complexity-related retention time robustness (important for example MS/MS scheduling/aiding selectivity) was examined by comparing retention times of the simple ExSMix proteotypic peptides with that of the ExSMix spiked to tryptic HCT15 cell lysate (serving as a complex matrix). The median change in retention time of the peptides in the ExSMix and the ExSMix spiked cell sample was significantly larger for the monoliths (-2.1 and $-1.6 \mathrm{~min}$, for the organic and silica monolith, respectively) compared with the particle packed columns $(-0.5$ and $-1.2 \mathrm{~min}$, for the totally porous and solid core particle packed columns, respectively, Supplementary Figure 8). The average retention time RSDs of complex samples were 0.8 (1.9), $0.6(1.0), 2.6(2.8)$ and $1.3(2.3) \%(\mathrm{n} \geq 3)$ for the Chromolith, Accucore, PepMap and PepSwift, respectively (largest variation in parenthesis) (Figure 1). Figure 2 shows extracted ion chromatograms of the representative $\beta$-catenin peptide LLNDEDQVVVNK in each sample chromatographed on the four column set-ups. The peak widths did not change as the sample complexity increased (between ExSMix and ExSMix added to the cell lysate), indicating no sign of column overload.

\section{Comparison of targeted nanoLC-MS/MS} performance: detecting Wnt proteins in colon cancer cells

The proteotypic peptides were subsequently searched for in an unspiked cell sample. For identification minimum three intense/descriptive MS/MS transitions were required. An additional criterion was that the retention time variation was maximum \pm 0.5 min relative to that of the ExSMix in spiked sample (matrix matching, see Supplementary Figure 9) to ensure very confident identification.

$\beta$-catenin (downstream target of $\mathrm{Wnt} /$ signaling) and GSK3 $\beta$ (a kinase crucial for $\mathrm{N}$-terminal phosphorylation of $\beta$-catenin that leads to its degradation) ( $\sim 60 \mathrm{ng} / \mu \mathrm{g}$ and $\sim 15 \mathrm{ng} / \mu \mathrm{g}$ sample), respectively) were clearly identifiable with all the columns with the abovementioned criteria. With the criteria employed the two

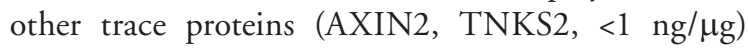
were however not identified. Notably, using just two intense/descriptive MS/MS transitions would cause false positives in our assay; for example, the $\mathrm{C}$-terminal HSSPSGTVAAR peptide of intact APC (not present in HCT15 colon cancer cells, due to a premature stop codon [26]) was falsely identified with otherwise same criteria (data not shown).

\section{Quantification with isotopically labeled internal standard}

Simultaneous protein quantification with western blot (WB) is time consuming, specificity is antibodydependent and values are often related to house-keeping proteins (e.g., Actin). LC-MS/MS is another alternative that allows for multiple proteins to be quantified with a high degree of specificity. For quantification in complex samples, isotopically labeled ISs are often added, either as peptides or proteins (e.g., AQUA peptides [27] or SILAC [19]). In this study, SILAC was used to label two cell lines that were pooled and used as an internal standard protein solution $\left(\mathrm{IS}_{\text {prot }}\right)$ in following experiments (preparation and workflow described in Materials and methods and Supplementary Figure 10). In contrast to for example, spiking with single IS peptides, the labeled mix is a 'universal' IS, also provides correction for protein digestion, SPE clean-up and MSresponse. Also the approach is simpler than producing recombinant-labeled IS proteins [28].

To see whether the solid core column (chosen due to best column performance, see above) would allow detecting changes in proteotypic peptide levels of $\beta$-catenin and GSK3 $\beta$, we selected the colon carcinoma cell lines HCT15, COLO320DM and SW480 cells (IS ${ }_{\text {prot }}$ added). Each were treated with a selective tankyrase inhibitor (G007-LK [17]) and subjected to quantification with LC-MS/MS and WB. $\beta$-catenin (the subject of the AXIN2/tankyrase2/APC/GSKbeta-containing destruction complex) could be relatively quantified with excellent precision (RSD 8\%) in these solutions with double complexity (sample + IS $_{\text {prot }}$ ) well within 20 min: Reduction of $\beta$-catenin following treatment with the selective tankyrase inhibitor G007-LK was observed in SW480 cells and correlated with results obtained with an established WB protocol (see Figure 3 and [16]). For levels of GSK3 $\beta$ and $\beta$-catenin in the other cell lines analyzed, see Supplementary Figure 11.

\section{Discussion}

We have compared some of the most common nanoLC columns/morphologies used for relatively fast, targeted proteomics, for determination of central proteins in the Wnt signal pathway. Using 30 min solvent gradients $\left(t_{M}\right.$ and $t_{G}$ was similar for all columns after optimization), the solid core par- 


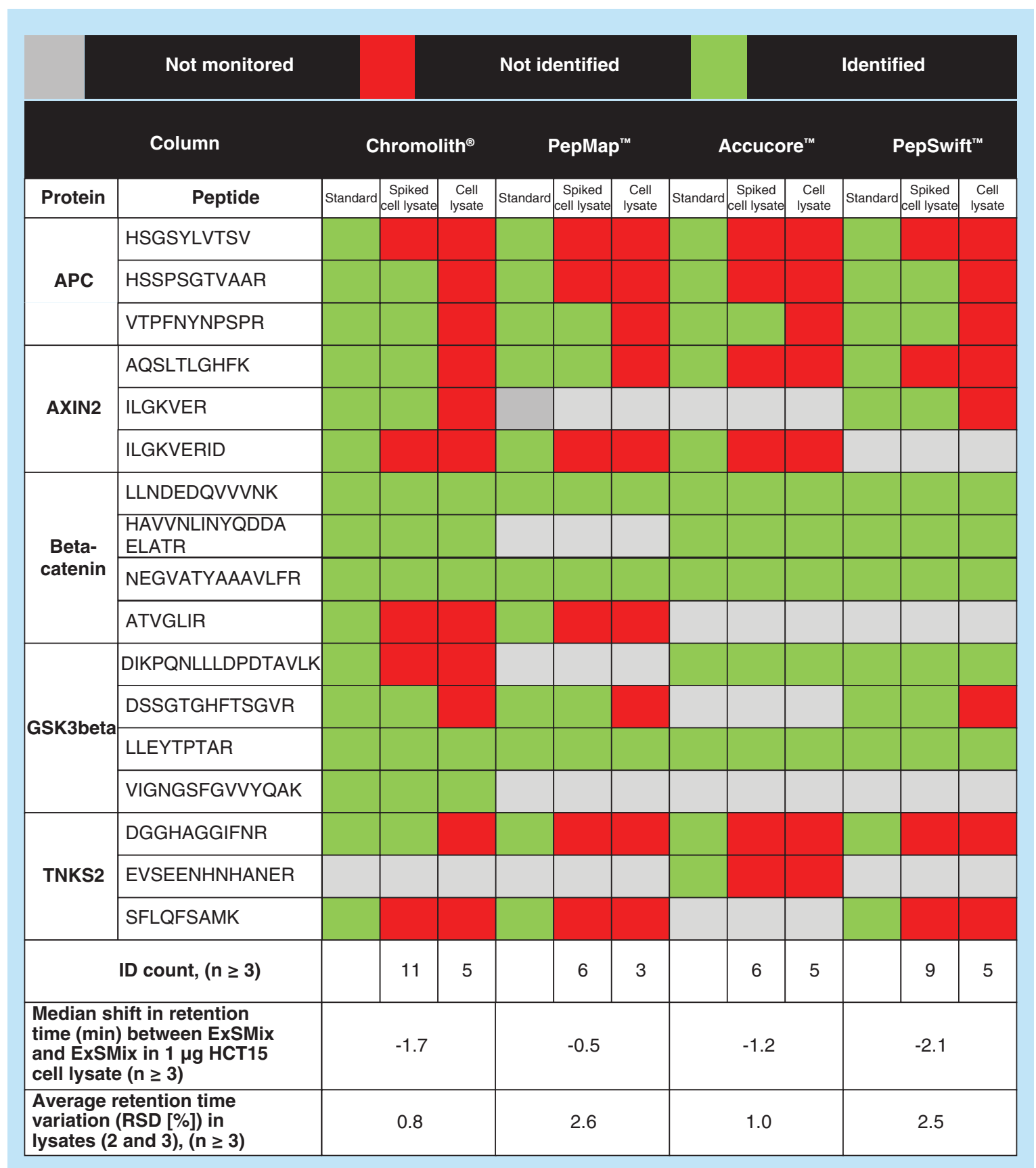

Figure 1. Peptide identification for each chromatographic column investigated. Standard is 0.5 ng ExSMix, Spiked cell lysate is $0.5 \mathrm{ng}$ ExSMix spiked into $1 \mu \mathrm{g} \mathrm{HCT} 15$ tryptic cell lysate and Cell lysate is $1 \mu \mathrm{g} \mathrm{HCT15}$ tryptic cell lysate (all in triplicates). Green equals identified, red not identified and gray not observed with ddMSMS. MS/MS extraction was done with $7 \mathrm{ppm}$ mass accuracy. Minimum three transitions were required for positive identification and not more than 0.5 min shift in $t_{R}$ between 2 and 3 were allowed for positive identification. At least three injections per group were used. ddMSMS: Data-dependent MS/MS; RSD: Relative standard deviation.

ticle packed nanocolumn provided the highest peak capacity and hence resolution, with the silica monolith at a clear second place. Similar results have been observed with larger-bore (i.e., larger inner diameter) columns [29], but it was not given that this would be the case for nano-scale columns, as successful packing/polymerization can be dependent on column diameter. For example, solid core particles packed in $2.1 \mathrm{~mm}$ ID columns have previously not been able to match the efficiency of comparable $4.6 \mathrm{~m}$ ID columns [30], while monolith columns are easier to prepare in capillary/nanoformat [31]. 

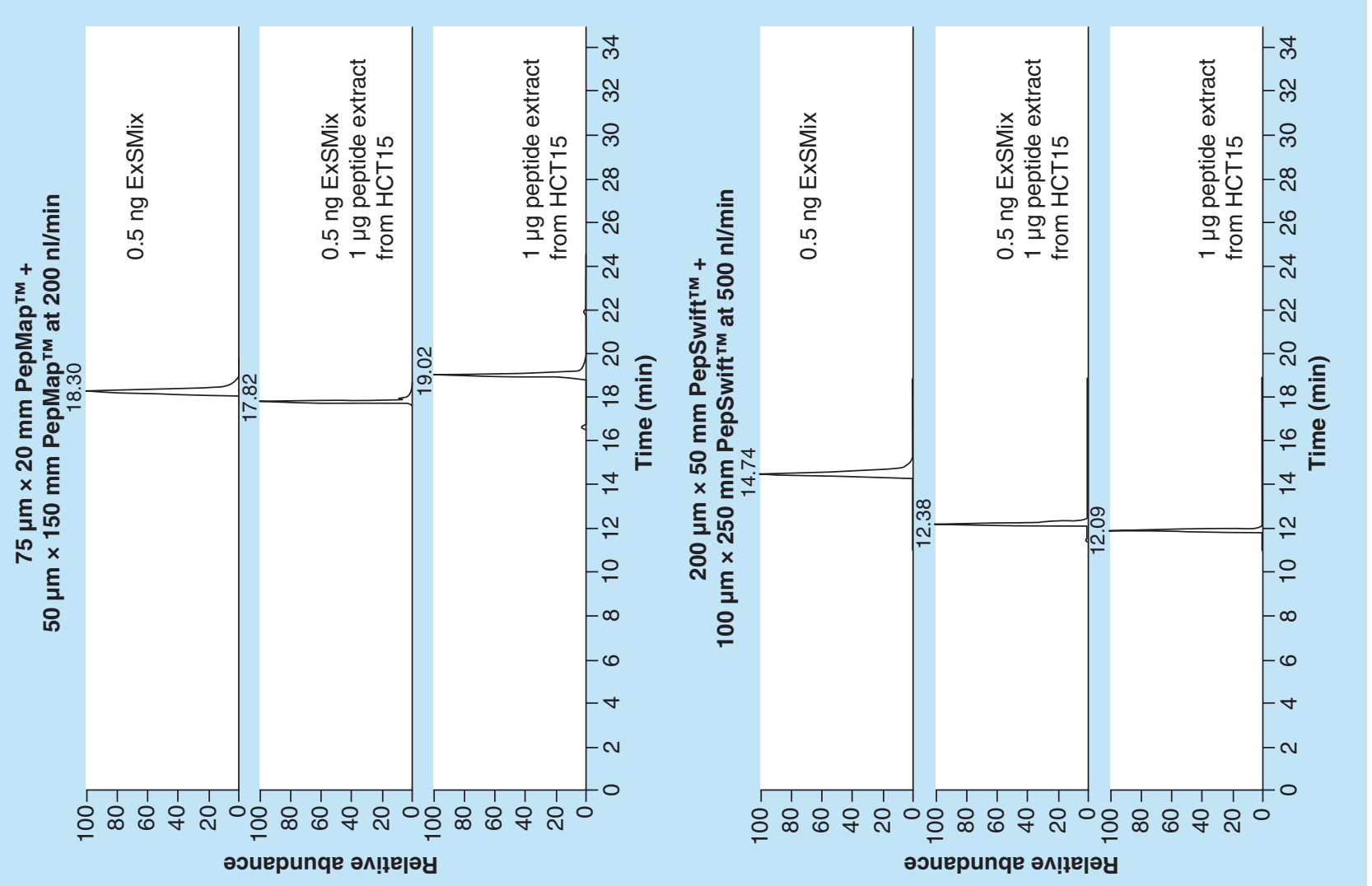

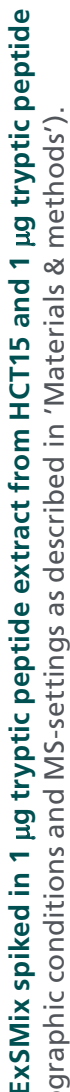

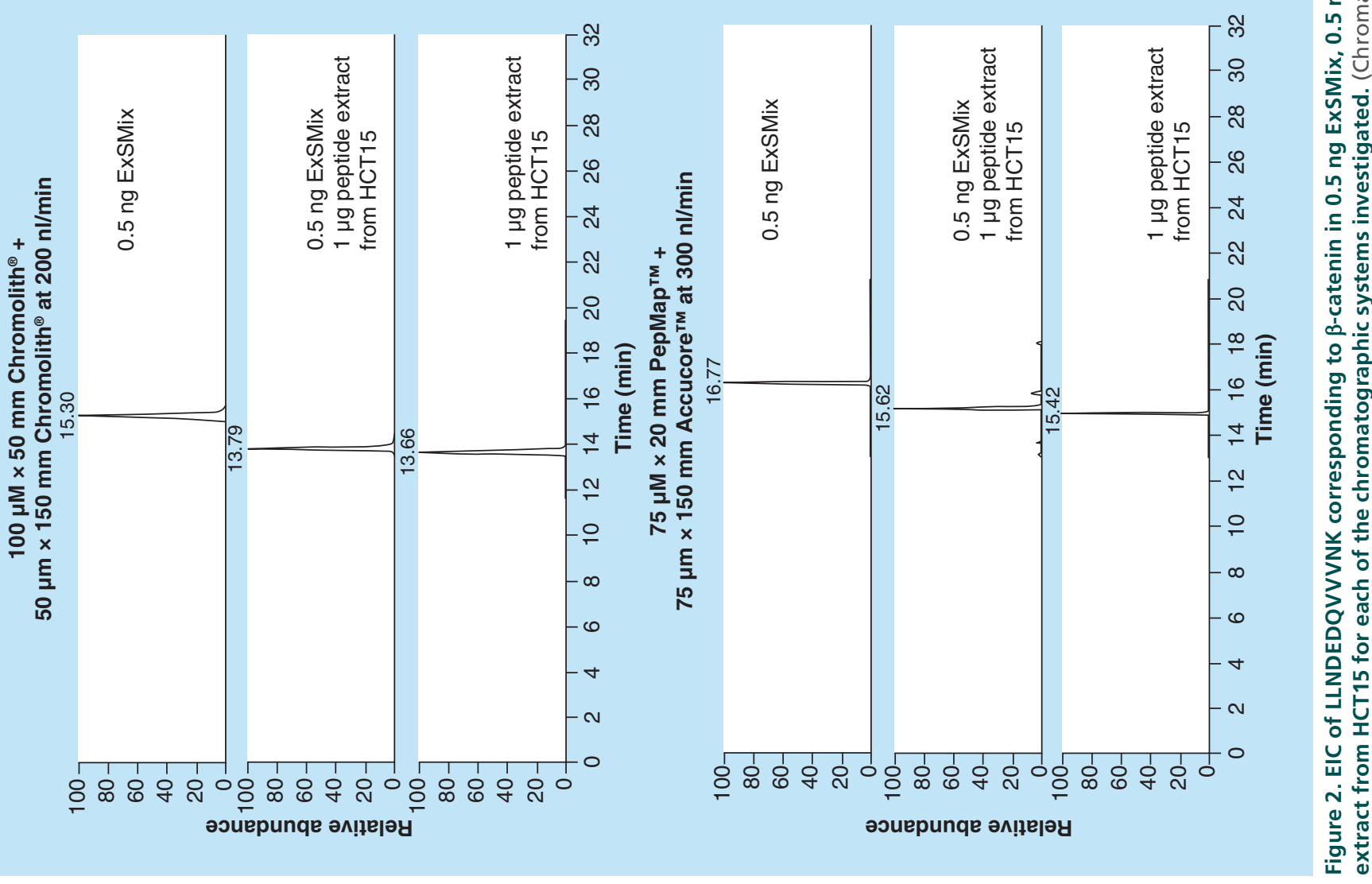




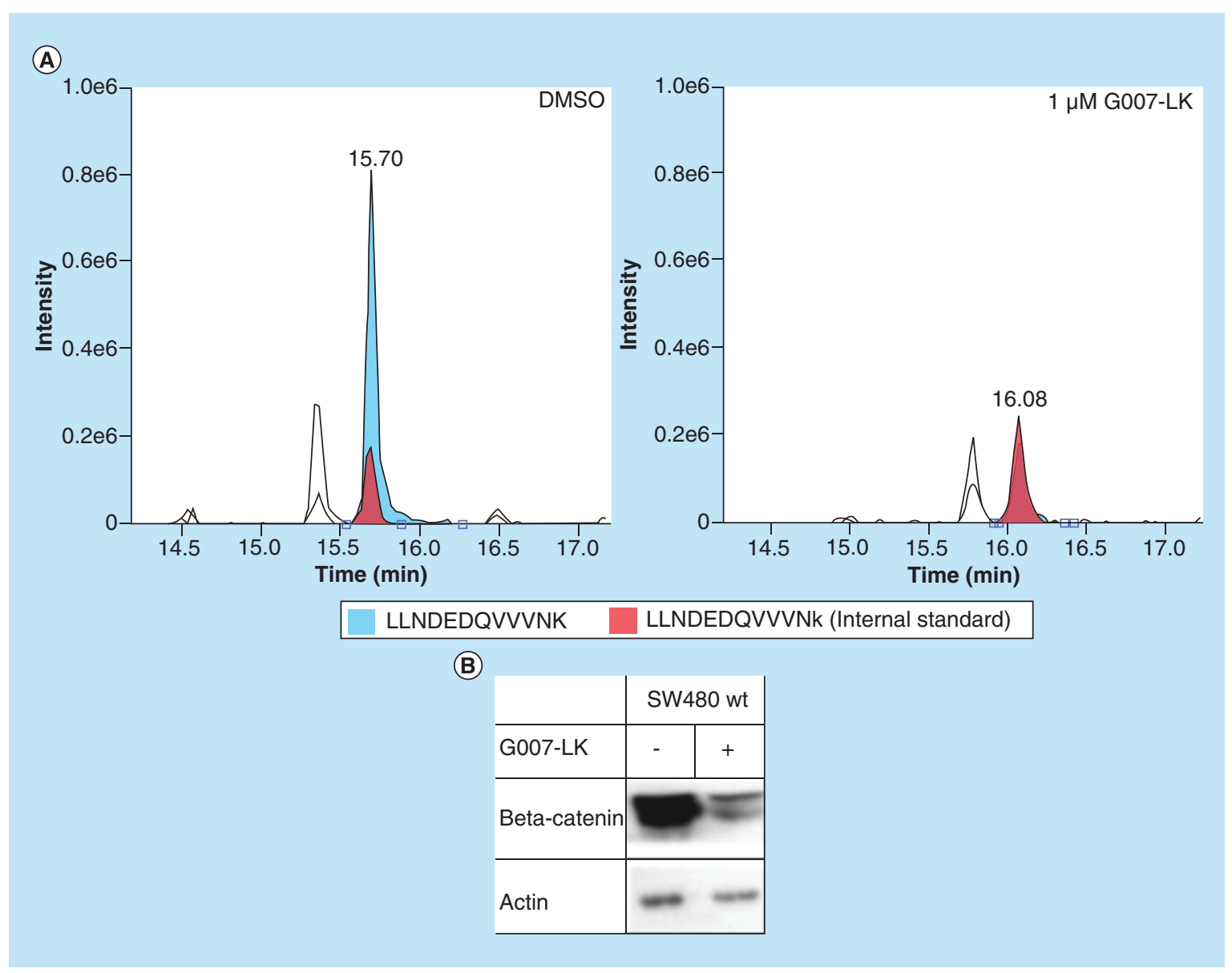

Figure 3. (A) EICS of LLNDEDQVVVNK (blue color, endogenous) and LLNDEDQVVVNk (red color, internal standard) in Dimethylsulfoxide and in $1 \mu \mathrm{M}$ G007-LK treated SW480 cells, respectively, analyzed by LC-MS/MS on the Accucore ${ }^{\mathrm{TM}}$ (Thermo Fischer Scientific, MA, USA) column using standard gradient conditions and MS/MS detection in duplexing mode with resolution at 35,000 and maximum injection time at 100 ms. (B) Western blot of total $\beta$-catenin and actin in Dimethylsulfoxide and $1 \mu \mathrm{M}$ G007-LK-treated SW480 cells. (Procedure in Supplementary Materials \& methods).

The column's retention time robustness (of importance for strict identification and MS/MS scheduling) differed significantly, with the solid core column having the best within-complex sample repeatability. The retention time robustness of the solid core particle packed column was somewhat surprising considering its lower surface area. We believe this factor was less important due to the use of a full porous particle packed precolumn. The columns were rather similar regarding other traits such as carryover and loading capacity.

Although the solid core column had arguably the best performance regarding peak capacity, there were no differences in the number of target proteins/proteotypic peptides detected in complex samples. It is possible that the differences between today's state-of-theart columns are to a large degree insignificant when handling complex samples? Performing untargeted proteomics further supported this hypothesis; the number of identified proteins was virtually identical when using different commercial columns (see

Supplementary Figure 12, Supplementary Information and Supplementary Excel File).

\section{Conclusion}

Is there convincing evidence that the choice of commercial nanoLC column will clearly affect success in relatively fast, targeted proteomics? Based on our case study of Wnt pathway proteins, our answer is 'no'. To enable more sensitive targeted proteomics, we believe that more focus should be on developing very narrow columns (low $\mu \mathrm{m}$ ID); such columns are operated at low flow rates (low $\mathrm{nl} / \mathrm{min}$ ), which is associated with a very low degree of ion suppression [32].

\section{Future perspective}

We believe that the field of proteomics will move to more hypothesis-driven research, with targeted methods being more important than the previous comprehensive approaches. Systems will probably develop into more plug-and-play solutions which enable labs to transfer 
from antibody-based techniques. Quick sample preparation and downscaling of columns will be important in the next years, as well as method specificity and robustness. We also believe that the mass spectrometers will have to be miniaturized in to fit the chromatographic systems.

\section{Supplementary data}

To view the supplementary data that accompany this paper, please visit the journal website at: www.future-science.com/ doi/full/10.4155/fsoa-2016-0014

\section{Author contributions}

Experimental design: T Vehus, K Erikstad Seterdal, S Krauss, E Lundanes, SR Wilson; conducting experiments: T Vehus, K Erikstad Seterdal; data evaluation: T Vehus, K Erikstad
Seterdal, S Krauss, E Lundanes, SR Wilson; writing manuscript: TVehus, K Erikstad Seterdal, S Krauss, E Lundanes, SR Wilson.

\section{Financial \& competing interests disclosure}

This research was funded through University of Oslo. The authors have no other relevant affiliations or financial involvement with any organization or entity with a financial interest in or financial conflict with the subject matter or materials discussed in the manuscript apart from those disclosed.

No writing assistance was utilized in the production of this manuscript.

\section{Open access}

This work is licensed under the Creative Commons Attribution 4.0 License. To view a copy of this license, visit http://creativecommons.org/licenses/by/4.0/

Executive summary

- Commercial nanoLC columns do not have significant performance difference for targeted determination of proteins in complex samples, even though they differ in chromatographic performance.

- Solid core and porous particle packed columns compared with organic and silica monoliths are more robust in terms of retention time shift in standards versus complex samples.

- Peak capacity does not affect the number of identified proteins in 30 min gradients.

- Sensitivity is not drastically affected in the flow range of 500-200 $\mathrm{nl} / \mathrm{min}$.

- Moderate abundant proteins; $\beta$-catenin and GSK3 $\beta$ can be quantified with low relative standard deviationsand correlate well to western blot results.

\section{References}

Papers of special note have been highlighted as:

- of interest; $\bullet \bullet$ of considerable interest

1 Picotti P, Aebersold R. Selected reaction monitoring-based proteomics: workflows, potential, pitfalls and future directions. Nat. Methods 9(6), 555-566 (2012).

- Important aspects of how to perform targeted proteomics experiments.

2 Liebler DC, Zimmerman LJ. Targeted quantitation of proteins by mass spectrometry. Biochemistry $52(22)$, 3797-3806 (2013).

3 Chen Y, Gruidl M, Remily-Wood E et al. Quantification of beta-catenin signaling components in colon cancer cell lines, tissue sections, and microdissected tumor cells using reaction monitoring mass spectrometry. J. Proteome Res. 9(8), 4215-4227 (2010).

4 Gallien S, Duriez E, Crone C, Kellmann M, Moehring T, Domon B. Targeted proteomic quantification on quadrupoleorbitrap mass spectrometer. Mol. Cell. Proteomics 11(12), 1709-1723 (2012).

- Introduction of high-resolution parallel reaction monitoring on orbitrap mass spectrometers.

5 Neue UD. Theory of peak capacity in gradient elution. J. Chromatogr. A 1079(1), 153-161 (2005).

6 Wang X, Stoll DR, Schellinger AP, Carr PW. Peak capacity optimization of peptide separations in reversed-phase gradient elution chromatography: fixed column format. Anal. Chem. 78(10), 3406-3416 (2006).
7 Marchetti N, Cavazzini A, Gritti F, Guiochon G. Gradient elution separation and peak capacity of columns packed with porous shell particles. J. Chromatogr. A 1163(1), 203-211 (2007).

8 Unger KK, Skudas R, Schulte MM. Particle packed columns and monolithic columns in high-performance liquid chromatography-comparison and critical appraisal. J. Chromatogr. A 1184(1), 393-415 (2008).

9 Eeltink S, Dolman S, Detobel F, Swart R, Ursem M, Schoenmakers PJ. High-efficiency liquid chromatographymass spectrometry separations with $50 \mathrm{~mm}, 250 \mathrm{~mm}$, and $1 \mathrm{~m}$ long polymer-based monolithic capillary columns for the characterization of complex proteolytic digests. J. Chromatogr. A 1217(43), 6610-6615 (2010).

10 Novakova L, Vaast A, Stassen C et al. High-resolution peptide separations using nano-lc at ultra-high pressure. J. Sep. Sci. 36(7), 1192-1199 (2013).

11 Zhou F, Lu Y, Ficarro SB, Webber JT, Marto JA. Nanoflow low pressure high peak capacity single dimension lc-ms/ms platform for high-throughput, in-depth analysis of mammalian proteomes. Anal. Chem. 84(11), 5133-5139 (2012).

12 Rogeberg M, Wilson SR, Malerod H, Lundanes E, Tanaka N, Greibrokk T. High efficiency, high temperature separations on silica based monolithic columns. J. Chromatogr. A 1218(41), 7281-7288 (2011).

13 Vaast A, Broeckhoven K, Dolman S, Desmet G, Eeltink $S$. Comparison of the gradient kinetic performance of silica monolithic capillary columns with columns packed 
with $3 \mu \mathrm{m}$ porous and $2.7 \mu \mathrm{m}$ fused-core silica particles. J. Chromatogr. A 1228, 270-275 (2012).

14 Macdonald BT, Tamai K, He X. Wnt/beta-catenin signaling: components, mechanisms, and diseases. Dev. Cell 17(1), 9-26 (2009).

15 Olsen PA, Solberg NT, Lund K et al. Implications of targeted genomic disruption of $\beta$-catenin in bxpc-3 pancreatic adenocarcinoma cells. PLoS ONE 9(12), e115496 (2014).

16 Lau T, Chan E, Callow M et al. A novel tankyrase smallmolecule inhibitor suppresses apc mutation-driven colorectal tumor growth. Cancer Res. 73(10), 3132-3144 (2013).

17 Voronkov A, Holsworth DD, Waaler J et al. Structural basis and sar for g007-lk, a lead stage 1,2,4-triazole based specific tankyrase 1/2 inhibitor. J. Med. Chem. 56(7), 3012-3023 (2013).

Wisniewski JR, Zougman A, Nagaraj N, Mann M. Universal sample preparation method for proteome analysis. Nat. Methods 6(5), 359-362 (2009).

- Easy sample preparation for bottom-up proteomics.

19 Ong SE, Mann M. A practical recipe for stable isotope labeling by amino acids in cell culture (silac). Nat. Protoc. 1(6), 2650-2660 (2006).

- Introduction of labeling which is important for reducing quantification errors in proteomics experiments.

20 Maclean B, Tomazela DM, Shulman N et al. Skyline: an open source document editor for creating and analyzing targeted proteomics experiments. Bioinformatics 26(7), 966-968 (2010).

-• Easy to use software for analyzing selected/parallell reaction monitoring data.

21 Consortium TU. Activities at the universal protein resource (uniprot). Nucleic Acids Res. 42(D1), D191-D198 (2014).

22 Kele M, Guiochon G. Repeatability and reproducibility of retention data and band profiles on reversed-phase liquid chromatography columns: IV. Results obtained with luna c18 (2) columns. J. Chromatogr. A 869(1), 181-209 (2000).

23 Kele M, Guiochon G. Repeatability and reproducibility of retention data and band profiles on six batches of monolithic columns. J. Chromatogr. A 960(1), 19-49 (2002).
24 Peterson AC, Russell JD, Bailey DJ, Westphall MS, Coon JJ. Parallel reaction monitoring for high resolution and high mass accuracy quantitative, targeted proteomics. Mol. Cell. Proteomics 11(11), 1475-1488 (2012).

25 Sun L, Zhu G, Dovichi NJ. Comparison of the ltq-orbitrap velos and the q-exactive for proteomic analysis of 1-1000 ng raw 264.7 cell lysate digests. Rapid Commun. Mass Spectrom. 27(1), 157-162 (2013).

26 Ikediobi ON, Davies H, Bignell G et al. Mutation analysis of 24 known cancer genes in the nci-60 cell line set. Mol. Cancer Ther. 5(11), 2606-2612 (2006).

27 Gerber SA, Rush J, Stemman O, Kirschner MW, Gygi SP. Absolute quantification of proteins and phosphoproteins from cell lysates by tandem ms. Proc. Natl Acad. Sci. USA 100 (12), 6940-6945 (2003).

28 Edfors F, Bostrom T, Forsstrom B et al. Immunoproteomics using polyclonal antibodies and stable isotope-labeled affinity-purified recombinant proteins. Mol. Cell. Proteomics 13(6), 1611-1624 (2014).

29 Beneito-Cambra M, Herrero-Martínez JM, Ramis-Ramos G, Lindner W, Lämmerhofer M. Comparison of monolithic and microparticulate columns for reversed-phase liquid chromatography of tryptic digests of industrial enzymes in cleaning products. J. Chromatogr. A 1218(41), 7275-7280 (2011).

30 Gritti F, Guiochon G. Repeatability of the efficiency of columns packed with sub- $3 \mu \mathrm{m}$ core-shell particles: part II. $2.7 \mu \mathrm{m}$ halo-es-peptide-c18 particles in $4.6 \mathrm{~mm}$ and $2.1 \mathrm{~mm}$ $\times 100 \mathrm{~mm}$ column formats. J. Chromatogr. A 1252, 31-44 (2012).

31 Ishizuka N, Kobayashi H, Minakuchi $\mathrm{H}$ et al. Monolithic silica columns for high-efficiency separations by highperformance liquid chromatography. J. Chromatogr. A 960(1), 85-96 (2002).

32 Schmidt A, Karas M, Dülcks T. Effect of different solution flow rates on analyte ion signals in nano-esi ms, or: when does esi turn into nano-esi? J. Am. Soc. Mass Spectrom. 14(5), 492-500 (2003). 